\title{
The Effect of Religious Identity on User Judgment of Website Quality
}

\author{
Ons Al-shamaileh ${ }^{1}$, Alistair Sutcliffe ${ }^{1}$, and Antonella De Angeli ${ }^{2}$ \\ ${ }^{1}$ Manchester Business School, \\ University of Manchester UK \\ ${ }^{2}$ University of Trento Italy \\ Alshamaileh.ons@gmail.com, \\ alistair.sutcliffe@mbs.ac.uk, \\ antonella.deangeli@disi.unitn.it
}

\begin{abstract}
The paper investigates the effect of users' religious identity on their judgments of website quality. Websites related to Islamic and Christian identities were evaluated by Christian and Muslim respondents. Aesthetics, usability, service quality, pleasurable interaction, content, website identity and overall judgment were assessed, showing that respondents were more positive to the website which related to their own belief but the effect was stronger with the Muslim sample. Interviews were conducted to support the above results with a non-religious well known branded website added. Respondents provided consistent evaluations preferring the website matching their beliefs but brand identity showed to be more important than the religious identity.
\end{abstract}

Keywords: User experience, user judgment, Religion, brand.

\section{Introduction}

A conceptual framework for user experience has suggested that the interaction with a product gives rise to emotions, attitudes and thoughts which will influence intentions and interactions with the product used over time; claiming that user experience is affected by individual differences such as knowledge, concerns, skills, personality and physical attributes [2]. Factors such as product, user, context of use and social and cultural factors are also claimed to affect the user experience [1]. To influence users' overall judgment, Organization brand has been shown in market related studies to have a positive effect of favorable brand on quality perceptions [5]. Research has covered several user characteristics and background aspects affecting website overall judgment. However, user religion as a factor affecting user experience has received little attention by researchers; further work on user religious identity is needed. This paper explores user social identity (religion) as one of the factors affecting user judgment of website quality ${ }^{1}$

${ }^{1}$ A composite of the factors measured in this study (aesthetics, usability, service quality, pleasurable interaction, content, website identity and overall judgment). 


\section{Method}

\subsection{Online Questionnaires}

Questionnaires explored the role of religion on user judgment of website quality. A sample of six websites from three different areas (health www.muslimhealthnetwork.org/, www.christianhospital.org/, books, www.islamicbookstore.com, www.christianbook.com and aid, www.muslimaid.org, www.christianaid.org/ ) associated to Muslim and Christian identities were randomly allocated to users. Respondents' viewed one website and evaluated it by completing an online questionnaire. 371 respondents took part in the online questionnaire, 167 respondents were Muslims; 147 were Christians, 44 atheists, 10 from other religion and three refused to declare their religion. 52\% of the sample was aged 1825, 36\% aged 26-35, 7\% 36-45 and 5\% were older. Only responses from Muslim and Christian respondents were considered in the analysis of this study. The questionnaire was divided into three parts, website evaluation, religious commitment [10] and demographic information. The first part of the questionnaire consisted of several scales; classical aesthetics [7], expressive aesthetics [7], usability [7], pleasurable interaction [7], service quality [7], information quality-content with a nine items was originally adapted from Bernier Instructional Design [3] symbolism [9], overall judgment and behavioral intentions. The total number of questions was 54 questions.

\subsection{Interviews}

Interviews were conducted to get a deeper insight of the effect of the website religious identity on respondents' evaluations. Brand was included as an additional factor in the interview study; to further examine the difference between social identity (religion) and brand. Twenty eight randomly selected respondents were interviewed. Fifteen were Muslims and thirteen were Christians, age range 22-34. Respondents viewed three websites; two were used in the survey (www.islamicbookstore.com and www.christianbook.com) with addition of a third -non religious- well known brand (http://bookshop.blackwell.co.uk). Participants were then interviewed to express their preference towards each website, and to indicate the most important features affected their decision. Interviews transcripts were coded to summarize respondents' opinions.

\section{Results}

Cronbach's alpha values ranged from 0.818 - to 0.961 for all scales. Results showed that religious identity is a strong influence. Two-way ANOVAs; (respondents religions* websites identities) results showed that website religion had a main effect on user judgment of aesthetics, usability, service quality, pleasurable interaction, content, website identity and overall judgment, with significant interactions of the website identity and the respondent religion for all variables except aesthetics and usability. One way ANOVAs were conducted to analyze differences between Muslim and Christian websites. Results showed that there was significant difference between Muslims and Christians evaluating Muslim websites in all dependent variables except 
classic aesthetic and usability; while only three factors; pleasurable interaction, symbolism and service quality were significant in evaluating Christian websites.

The Christian sample showed a bimodal distribution and was divided into two groups; strong and weak believers. Using a median split; $84<5$ and were categorized as weak believers. $63>5$ and were categorized as strong believers. One way ANOVAs of the Christian respondents (strong and weak believers) showed no differences while evaluating Muslim websites. However, all scales apart from classic aesthetics and usability were significant while evaluating Christian websites. Strong Christian believers rated Christian websites higher than weak Christian believers, while the strength of religious beliefs did not have an effect when evaluating websites from a non matching identity. Respondents were asked to rank criteria according to their importance in influencing their overall judgments. Content was the most important criterion in all evaluations apart from Muslims evaluating the Christian website where usability was ranked number one and the neutral (branded) website where ID was ranked as the most important criterion. Usability was highly ranked while aesthetics and pleasurable interaction were least important.

The interview results supported the survey indicating that respondents' prefer matching identity websites. Respondents explicitly mentioned that website identity and content are the reasons of preferring the matching website rather than design quality; (Christian on a Muslim website) "everything in the website looks neutral to me apart from the content and religious identity which I consider as negative since it's not of my interest". Similarly; a Muslim on the Christian website; "I will not visit it again; good in terms of design not content". A curiosity effect appeared for Christians expressing interest in Islam as a new experience. "It is something new and everything new you become curious to see what it is about". A possible social sub identity emerged in the Christian sample where three respondents did not like the content of the matching identity website because it followed an approach that did not match their beliefs; e.g. "The content of the website is pushy and not really related to my beliefs, though I am a Christian I feel the content approach is American which is different from mine". Brand showed a strong effect on users' evaluations, 9/13 Christians and 12/16 Muslims favored branded website over websites with religious identity. Respondents were asked to assess each criterion by indicating (positive, negative or neutral). The net ratings of criteria excluding neutral evaluations were calculated. In matching identity websites; respondents were more positive rating content and website identity in matching than in non matching identity websites. But overall; Muslims and Christians preferred the identity of the branded website which they were all familiar with.

\section{Discussion}

Results showed that religion as a form of user social identity had an important effect on user judgment of website quality, which agrees with Hartmann et al. [6] indicating that users' background influence the decision making process. This paper showed that websites with religious identity affected users' perception of service quality, pleasurable interaction, content, overall judgment but not usability and aesthetics. People may be separating evaluation of usability and aesthetics from identity and 
treating them objectively. Respondents favored matching identity websites and evaluated them more favorably than websites from other religions (both Muslims and Christians); which partially agrees with Siala et al [8] results that only Muslims trusted matching identity websites while Christians favored neutral websites. Brand affected respondents' judgment of content, service quality, usability and aesthetics which agrees with De Angeli et al [4] who demonstrated that people who have positive attitudes towards the website brand were more positive in the evaluation of aesthetics, pleasure and usability. This paper demonstrated clear effects of religion on user judgment of website quality with regards to the websites that has a religious identity regardless of its domain; however, some limitations should be noted. The study consisted of several measures representing opinions; these opinions may differ with intentions or actual actions i.e. respondents may have different judgment while only viewing a charity website and donating to that website.

\section{Refrences}

1. Arhippainen, L., Tähti, M.: Empirical Evaluation of User Experience in Two Adaptive Mobile Application Prototypes. In: Proceedings of the 2nd International Conference on Mobile and Ubiquitous Multimedia, pp. 27-34. ACM, Norrköping (2003)

2. Beauregard, R., Corriveau, P.: User Experience Quality: A Conceptual Framework for Goal Setting and Measurement. In: Duffy, V.G. (ed.) Digital Human Modeling. LNCS, pp. 325332 (2007)

3. De Angeli, A., Sutcliffe, A., Hartmann, J.: Interaction, usability and aesthetics: what influences users' preferences? In: DIS 2006: Proceedings of the 6th Conference on Designing Interactive Systems, pp. 271-280. ACM, New York (2006)

4. De Angeli, A., Hartmann, J., Sutcliffe, A.G.: The Effect of Brand on the Evaluation of Websites. Interact (2), 638-651 (2009)

5. Dodds, W.B., Monroe, K.B., Grewal, D.: Effects of Price, Brand and Store Information on Buyers' Product Evaluations. Journal of Marketing Research 28, 307-319 (1991)

6. Hartmann, J., Sutcliffe, A.G., De Angeli, A.: Towards a Theory of User Judgment of Aesthetics and user Interface Quality. ACM Transactions on Computer-Human Interaction (TOCHI) 15(4), Article No. 15 (2008)

7. Lavie, T., Tractinsky, N.: Assessing Dimensions of Perceived Visual Aesthetics of Web Sites. International Journal of Human-Computer Studies 60(3), 269-298 (2004)

8. Siala, H., O'Keefe, R.M., Hone, K.S.: The impact of religious affiliation on trust in the context of electronic commerce. Interacting with Computers 16, 7-27 (2004)

9. Tractinsky, N., Zmiri, D.: Exploring Attributes of Skins as Potential Antecedents of Emotion in HCI. In: Fishwick, P. (ed.) Aesthetic Computing, MIT Press, Cambridge (2005) (in press)

10. Worthington Jr., E.L., Wade, N.G., Hight, T.L., McCullough, M.E., Berry, J.T., Ripley, J.S., Berry, J.W., Schmitt, M.M., Bursley, K.H.: The religious commitment inventory-10: development, refinement and validation of a brief scale for research and counseling. Journal of Counselling Psychology 50(1), 84-96 (2003) 